\section{A survey of measures used for the prevention of postoperative endophthalmitis after cataract surgery in the United Kingdom}

Department of

Ophthalmology,

Hinchingbrooke Hospital,

Huntingdon,

Cambridgeshire, UK

Correspondence: P GordonBennett,

Department of

Ophthalmology,

Hinchingbrooke Hospital, Huntingdon,

Cambridgeshire, PE29 6NT, UK

Tel: +44 1480416414 ;

Fax: +44 1480416516 .

E-mail: patelgordon@

yahoo.co.uk

Received: 26 May 2006 Accepted: 30 October 2006 Published online: 15

December 2006

The results of this study have been presented as a poster at the Annual Congress of the Royal College of Ophthalmologists on May 23-25, 2006

\begin{abstract}
Purpose This study investigates the current practice of United Kingdom (UK) ophthalmologists in perioperative antibiotic and antiseptic use in cataract surgery. Materials and methods A telephone interview survey was conducted with ophthalmic staff at all ophthalmic training units in the UK in October and November 2005.
\end{abstract}

Results The practices of a total of 800 consultants were ascertained. Preoperatively, $795(99.4 \%)$ surgeons used povidone-iodine to prepare the skin. In all, $558(69.8 \%)$ instilled 5 or $10 \%$ povidone-iodine in the conjunctival sac; $47(5.9 \%)$ gave preoperative antibiotic eyedrops. Intraoperatively, intracameral antibiotics were given either as a bolus [80 (10.0\%) intracameral cefuroxime, 29 (3.6\%) intracameral vancomycin] or in the irrigating fluid [33 $(4.1 \%)$ vancomycin]. $48(6.0 \%)$ gave subconjunctival gentamycin only routinely, $531(66.4 \%)$ gave subconjunctival cefuroxime, and $39(4.9 \%)$ gave other subconjunctival antibiotics. A single dose of topical antibiotics was given by 134 (16.8\%) surgeons.

Postoperatively, $515(64.4 \%)$ used a combination steroid and neomycin eyedrop, and $213(26.6 \%)$ gave a separate steroid and chloramphenicol eyedrop.

Conclusions This study reveals wide variations in the choice and duration of antibiotics used by UK ophthalmologists. The predominant methods of intraoperative prophylaxis are subconjunctival cefuroxime and intracameral cefuroxime. Most surgeons
P Gordon-Bennett, A Karas, D Flanagan, C Stephenson and M Hingorani used a neomycin eyedrop for postoperative prophylaxis.

Eye (2008) 22, 620-627; doi:10.1038/sj.eye.6702675; published online 15 December 2006

Keywords: antibiotic; cataract surgery; postoperative endophthalmitis; prevention; prophylaxis

\section{Introduction}

There is widespread variation in the prophylactic measures used to prevent endophthalmitis following cataract surgery ${ }^{1}$ but in the light of rising endophthalmitis incidence rates $^{2,3}$ and new scientific evidence, a reassessment of methods is required. Although rare, endophthalmitis carries a devastating prognosis, with only $33 \%$ of patients achieving visual acuity better than $6 / 12 .{ }^{4}$ Establishing sound practice patterns to prevent postoperative endophthalmitis (POE) is therefore essential.

The rarity of POE has resulted in a paucity of high-quality studies on the effect of prophylactic measures on incidence rates. Most endophthalmitis prophylaxis guidelines, such as those from the Royal College of Ophthalmologists (RCO) ${ }^{5}$ and the American Academy of Ophthalmology (AAO), ${ }^{6}$ leave the details of antibiotic use to the individual surgeon's discretion, although all state the use of povidone-iodine $5-10 \%$ solution into the conjunctival sac prior to surgery is mandatory. The European Society of Cataract and Refractive Surgeons (ESCRS) guidelines on prevention of 
POE recommends intracameral cefuroxime and does not encourage subconjunctival or infusion antibiotics. ${ }^{7}$

The aim of this study was to ascertain the antibiotic and antiseptic prophylaxis practice of UK ophthalmologists for POE in cataract surgery, identify variations in practice and to compare practice with current guidelines and best available evidence.

\section{Materials and methods}

An up to date list of all ophthalmic hospitals in the National Health Service (NHS) or Health and Social Services (HSS), and the numbers of consultant ophthalmologists in each eye unit, were obtained from the RCO Directory of Training Posts $2005-6^{8}$ and the Directory of Ophthalmology Care. ${ }^{9}$ Telephone interviews were conducted with the on-call ophthalmic medical staff in all 159 UK ophthalmic units in October and November 2005. Telephone calls were made by the same individual (PGB). A response was recorded as not available if three separate calls on different dates to the same department elicited no response. No attempt was made to contact private hospitals or Independent Sector Treatment Centres.

The units were classified as teaching/university hospitals or district general hospitals and the status of the responding member of staff recorded. Questions were asked to ascertain the number of consultant cataract surgeons in the unit, and the antibiotic and antiseptic prophylaxis used preoperatively, intraoperatively and postoperatively by each consultant; consultants were not named. Preoperative measures were defined as those used before the cataract operation commenced and included preoperative antibiotics (single dose or short course), skin disinfection, and povidone-iodine in the conjunctival sac either as formal instillation or during skin antisepsis allowing overspill into the conjunctival sac. Intraoperative measures referred to antibiotics given in the infusion or irrigating fluid, as an intracameral injection, subconjunctival injection or as topical antibiotic/antiseptic at the end of the operation. Postoperative measures were those used after the patient departed from the operating table. Questions were asked in an open-ended manner initially and clarified by providing options from which to choose. Validation was performed by telephoning $40 \%$ of hospitals on more than one occasion and interviewing a different staff member.

\section{Results}

\section{Response rate and validation}

Responses were obtained from 126 units (24 university hospitals (UH) and 102 district general hospitals (DGH)), about the practices of each consultant cataract surgeon. The status of responding staff was senior house officer $(97 \%)$, registrar $(1 \%)$, or consultant $(1 \%)$. In the 126 eye units, there were 800 consultant cataract surgeons. The total number of consultant ophthalmologists in the NHS/HSS was 1030. It was not possible to obtain the total number of consultant cataract surgeons in the NHS/ HSS but we estimate this total to be 900 . The response rate is therefore 800 out of $900(88.9 \%)$. Validation revealed a $100 \%$ correlation of results obtained at different times for the same department.

\section{Preoperative prophylaxis}

The vast majority of surgeons $(99.4 \%)$ used povidoneiodine (or chlorhexidine if iodine-allergic) to prepare the skin. Just over two-thirds used 5 or $10 \%$ povidone-iodine in the conjunctival sac, either as formal instillation of $5 \%$ povidone-iodine or instillation on the ocular surface during skin preparation with $10 \%$ povidone-iodine (Table 1).

Preoperative topical antibiotic use is shown in Table 1. Most surgeons did not use preoperative antibiotic eyedrops and, of those that did, the most common method was a single dose of chloramphenicol. One quarter used neither topical antibiotic nor povidoneiodine.

\section{Intraoperative prophylaxis}

Only four $(0.5 \%)$. consultants used no form of intraoperative antibiotic. The predominant form of intraoperative prophylaxis was subconjunctival antibiotic $(79.3 \%)$ followed by intracameral injection of antibiotic (13.6\%) and antibiotic in the infusion (4.1\%).

\section{Subconjunctival antibiotics}

The majority of consultants used subconjunctival cefuroxime (Table 1). Other subconjunctival antibiotics used were gentamycin (48), vancomycin (12), ceftazidime (11), cefotaxime (6), cefradine (5), and amikacin (5).

\section{Intracameral antibiotics}

In all, $142(17.7 \%)$ consultants gave antibiotics directly into the anterior chamber, as a bolus at the end or as an infusion (Table 1). Only vancomycin was used for infusion.

\section{Topical antibiotics/antiseptic}

Antibiotic eyedrops were predominantly used in combination with either subconjunctival or intracameral antibiotic. Very few consultants used antibiotic eyedrops as the only means of intraoperative prophylaxis and these were chloramphenicol combined with gentamycin 
Table 1 Perioperative prophylaxis methods: the numbers and percentages of consultants using each method

\begin{tabular}{|c|c|c|}
\hline \multirow[t]{2}{*}{ Method } & \multicolumn{2}{|c|}{ Consultant cataract surgeons } \\
\hline & $\begin{array}{c}\text { Total } \\
(\mathrm{N}=800)\end{array}$ & $\begin{array}{l}\text { Percentage } \\
(95 \% \mathrm{CI})\end{array}$ \\
\hline \multicolumn{3}{|l|}{ Preoperative eyedrops } \\
\hline \multicolumn{3}{|l|}{ Antibiotic } \\
\hline Chloramphenicol stat & 31 & $3.9(2.7-5.5)$ \\
\hline Chloramphenicol $\mathrm{qds} \times 3$ days & 9 & $1.1(0.6-2.1)$ \\
\hline Ofloxacin stat & 7 & $0.9(0.4-1.8)$ \\
\hline Total antibiotics & 47 & $5.9(4.4-7.7)$ \\
\hline Nil & 753 & $94.1(92.3-95.5)$ \\
\hline \multicolumn{3}{|l|}{ Antiseptic } \\
\hline Povidone-iodine/chlorhexidine & 558 & $69.8(66.5-72.8)$ \\
\hline Nil & 242 & $30.2(27.2-33.5)$ \\
\hline Total antibiotic or antiseptic & 598 & $74.8(71.6-77.6)$ \\
\hline No antibiotic or antiseptic & 202 & $25.2(22.4-28.4)$ \\
\hline \multicolumn{3}{|l|}{ Intraoperative } \\
\hline \multicolumn{3}{|l|}{ SC antibiotic } \\
\hline Gentamycin & 48 & $6.0(4.6-7.9)$ \\
\hline Cefuroxime & 531 & $66.4(63.0-69.6)$ \\
\hline Cefuroxime + gentamycin & 16 & $2.0(1.2-3.2)$ \\
\hline Other & 39 & $4.9(3.6-6.6)$ \\
\hline Total antibiotics & 634 & $79.3(76.3-81.9)$ \\
\hline Nil & 166 & $20.7(18.1-23.7)$ \\
\hline \multicolumn{3}{|l|}{ IC antibiotic } \\
\hline Cefuroxime bolus & 80 & $10.0(8.1-12.3)$ \\
\hline Vancomycin bolus & 29 & $3.6(2.5-5.2)$ \\
\hline Vancomycin infusion & 33 & $4.1(2.9-5.7)$ \\
\hline Nil & 658 & $82.2(79.4-84.7)$ \\
\hline \multicolumn{3}{|l|}{ Antibiotic/antiseptic eyedrops } \\
\hline Eyedrops with SC/IC antibiotic & 114 & $14.2(12-16.8)$ \\
\hline Eyedrops alone & 20 & $2.5(1.6-3.8)$ \\
\hline Total eyedrops & 134 & $16.8(14.3-19.5)$ \\
\hline Nil & 666 & $83.2(80.5-85.7)$ \\
\hline Gentamycin & 39 & $4.9(3.6-6.6)$ \\
\hline Chloramphenicol & 100 & $12.5(10.4-15.0)$ \\
\hline Povidone-iodine & 20 & $2.5(1.6-3.8)$ \\
\hline Fusidic acid & 6 & $0.8(0.3-1.6)$ \\
\hline \multicolumn{3}{|l|}{ Postoperative antibiotic drops } \\
\hline $\begin{array}{l}\text { Polymyxin B and } \\
\text { neomycin (maxitrol) }\end{array}$ & 315 & $39.4(36.0-42.8)$ \\
\hline Neomycin (betnesol-N) & 200 & $25.0(22.1-28.1)$ \\
\hline Neomycin all & 515 & $64.4(61-67.6)$ \\
\hline Chloramphenicol & 213 & $26.6(23.7-29.8)$ \\
\hline Tobramycin (tobradex) & 29 & $3.6(2.5-5.2)$ \\
\hline Flouroquinolone & 16 & $2.0(1.2-3.2)$ \\
\hline Nil (steroid only) & 25 & $3.1(2.1-4.6)$ \\
\hline Other & 2 & $0.2(0.07-0.9)$ \\
\hline
\end{tabular}

Preoperative eyedrops

Chloramphenicol stat

Chloramphenicol qds $\times 3$ days

Ofloxacin stat

Total antibiotics

Antiseptic

Povidone-iodine/chlorhexidine

Total antibiotic or antiseptic

No antibiotic or antiseptic

ntraoperative

Cefuroxin

Cefuroxime + gentamycin

Total antibiotics

antibiotic

Cefuroxime bolus

ancomycin bolus

Vancomycin infusion

Antibiotic/antiseptic eyedrops

Eyedrops with SC/IC antibiotic 114

Eyedrops alone

Nil

Gentamycin

Chloramphenicol

Povidone-iodin

Postoperative antibiotic drops

Polymyxin B and

Neomycin all

Chloramphenicol

Tobramycin (tobradex)

\section{Postoperative prophylaxis}

The majority of consultants used an eyedrop containing neomycin and steroid, and most of the remainder used chloramphenicol (Table 1). In all, 560 (70\%) of surgeons used the antibiotic eyedrop for duration greater than 1 week (2-4 weeks).

\section{Type of hospital and size of department}

Significantly more UH consultants than DGH consultants used conjunctival povidone-iodine (Table 2).

Preoperative and intraoperative antibiotic eyedrops were used more in the DGHs. DGH surgeons were significantly in favour of combined steroid-neomycin drops postoperatively whereas only half of $\mathrm{UH}$ consultants used these, the rest using predominantly chloramphenicol eyedrops.

There were fewer differences related to the size of the department, but preoperative chloramphenicol was used more, and conjunctival povidone-iodine less, by smaller departments (Table 3). Intracameral vancomycin use was confined to intermediate-sized departments.

\section{Discussion}

We present up-to-date information on prophylactic antibiotic and antiseptic use in cataract surgery in the UK. The survey achieved a high response rate of $88.9 \%$, exceeding the response rates from previous studies. ${ }^{10,11}$ It provides the first data on the use of intracameral antibiotics. This is also the first survey on the subject to employ telephone interviews for data collection and the method offers advantages over postal surveys, as direct dialogue between the person conducting the survey and the person being questioned allows immediate clarification of answers and possible uncertainties.

The method also achieves a high response rate. Validation by repeated telephone interviews on different occasions with new individuals from the same ophthalmic unit, ensured that the data obtained for each institution was accurate. This survey collected data on the methods used for prophylaxis of endophthalmitis by consultant ophthalmologists working in 126 out of the 159 NHS Ophthalmic units offering training. A sample of this size is likely to be an accurate reflection of current cataract surgical practice in the UK.

\section{Preoperative prophylaxis}

Povidone-iodine antisepsis

Povidone-iodine $10 \%$ solution (or chlorhexidine if allergy) is recommended for preparation of the skin as a or $1 \%$ povidone-iodine, or a neomycin-steroid eyedrop. $6(0.7 \%)$ consultants used povidone-iodine drops as the only intraoperative prophylactic measure. 
Table 2 Perioperative prophylaxis method and the number and percentage of consultant cataract surgeons by hospital type

\begin{tabular}{|c|c|c|c|c|}
\hline \multirow[t]{2}{*}{ Method } & \multicolumn{4}{|c|}{ Consultant cataract surgeons and hospital type } \\
\hline & $\begin{array}{l}\text { Number of } \\
\text { UH surgeons }\end{array}$ & $\begin{array}{l}\% \text { of UH surgeons } \\
\text { (of } \mathrm{n}=257)\end{array}$ & $\begin{array}{c}\text { Number of } \\
\text { DGH surgeons }\end{array}$ & $\begin{array}{l}\text { \% of DGH surgeons } \\
\quad(\text { of } \mathrm{n}=543)\end{array}$ \\
\hline \multicolumn{5}{|l|}{ Preoperative eyedrops } \\
\hline \multicolumn{5}{|l|}{ Antibiotic } \\
\hline Chloramphenicol stat & 1 & 0.4 & 30 & 5.5 \\
\hline Chloramphenicol course & 0 & 0 & 9 & 1.6 \\
\hline Ofloxacin & 0 & 0 & 7 & 1.3 \\
\hline Total antibiotics & 1 & 0.4 & 46 & 8.5 \\
\hline Nil & 256 & 99.6 & 497 & $91.5 P<0.001,1 \mathrm{df}$ \\
\hline \multicolumn{5}{|l|}{ Antiseptic } \\
\hline Povidone-iodine/chlorhexidine & 213 & 82.9 & 345 & 63.5 \\
\hline Nil & 44 & 17.1 & 198 & $36.5 P<0.001,1 \mathrm{df}$ \\
\hline Total antibiotic or antiseptic & 214 & 83.3 & 384 & 70.7 \\
\hline No antibiotic or antiseptic & 43 & 16.7 & 159 & $29.3 P<0.001,1 \mathrm{df}$ \\
\hline \multicolumn{5}{|l|}{ Intraoperative } \\
\hline \multicolumn{5}{|l|}{ SC antibiotic } \\
\hline Gentamycin & 10 & 3.9 & 38 & 7 \\
\hline Cefuroxime & 175 & 68.1 & 356 & 65.5 \\
\hline Cefuroxime + gentamycin & 0 & 0 & 16 & 2.9 \\
\hline Other & 18 & 7 & 21 & 3.9 \\
\hline Total antibiotics & 203 & 79 & 431 & 79.4 \\
\hline Nil & 54 & 21 & 112 & 20.6 \\
\hline \multicolumn{5}{|l|}{ IC antibiotic } \\
\hline Cefuroxime bolus & 31 & 12.1 & 49 & 9 \\
\hline Vancomycin bolus & 7 & 2.7 & 22 & 4 \\
\hline Vancomycin infusion & 8 & 3.1 & 25 & 4.6 \\
\hline Nil & 211 & 82.1 & 447 & 82.3 \\
\hline \multicolumn{5}{|l|}{ Antibiotic/antiseptic eyedrops } \\
\hline Eyedrops with SC/IC antibiotic & 13 & 5 & 101 & 18.6 \\
\hline Eyedrops alone & 0 & 0 & 20 & 3.7 \\
\hline Total eyedrops & 13 & 5 & 121 & 22.3 \\
\hline Nil & 244 & 95 & 422 & $77.7 P<0.001,1 \mathrm{df}$ \\
\hline Gentamycin & 12 & 4.7 & 27 & 5 \\
\hline Chloramphenicol & 13 & 5 & 87 & 16 \\
\hline Povidone-iodine & 0 & 0 & 20 & 3.7 \\
\hline Fusidic acid & 0 & 0 & 6 & 1.1 \\
\hline \multicolumn{5}{|l|}{ Postoperative antibiotic drops } \\
\hline Polymyxin B and neomycin (maxitrol) & 65 & 25.3 & 250 & 46 \\
\hline Neomycin (betnesol-N) & 61 & 23.7 & 139 & 25.6 \\
\hline Neomycin total & 126 & 49 & 389 & 71.6 \\
\hline Chloramphenicol & 105 & 40.8 & 108 & $19.9 P<0.001,3 \mathrm{df}$ \\
\hline Tobramycin, fluoroquinolone, other & 13 & 5 & 34 & 6.3 \\
\hline Nil (steroid only) & 13 & 5 & 12 & 2.2 \\
\hline
\end{tabular}

$10 \%$ solution ${ }^{12}$ and almost all surgeons surveyed complied.

A single topical application of $5 \%$ povidone-iodine in the conjunctival sac was the first convincingly proven prophylactic measure in reducing the rate of POE. ${ }^{13,14}$ Povidone-iodine achieves $96.7 \%$ bacterial kill within one minute of irrigation. ${ }^{15}$ However, in our survey nearly one third of consultants were reported as not employing this essential prophylactic measure.

\section{Antibiotic eyedrops}

The ESCRS study has concluded that although the use of perioperative levofloxacin eyedrops as prophylaxis was also associated with a reduction in the observed 
Table 3 Perioperative prophylaxis method and the number and percentage of cataract surgeons by the size of the eye department

\begin{tabular}{|c|c|c|c|c|c|c|}
\hline \multirow[t]{3}{*}{ Perioperative prophylactic method } & \multicolumn{6}{|c|}{ Size of department (number of consultant cataract surgeons) } \\
\hline & \multicolumn{2}{|c|}{4 or less $\mathrm{N}=126$} & \multicolumn{2}{|c|}{$5-9 \mathrm{~N}=410$} & \multicolumn{2}{|c|}{10 or more $\mathrm{N}=264$} \\
\hline & Number & $\%$ & Number & $\%$ & Number & $\%$ \\
\hline \multicolumn{7}{|l|}{ Preoperative eyedrops } \\
\hline \multicolumn{7}{|l|}{ Antibiotic } \\
\hline Chloramphenicol stat & 16 & 12.7 & 1 & 0.2 & 14 & 5.3 \\
\hline Chloramphenicol course & 3 & 2.4 & 6 & 1.5 & 0 & 0 \\
\hline Ofloxacin & 0 & 0 & 7 & 1.7 & 0 & 0 \\
\hline Total antibiotic & 19 & 15.1 & 14 & 3.4 & 14 & 5.3 \\
\hline Nil & 107 & 84.9 & 396 & 96.6 & 250 & $94.7 P<0.001,2 \mathrm{df}$ \\
\hline \multicolumn{7}{|l|}{ Antiseptic } \\
\hline Povidone-iodine/chlorhexidine & 75 & 59.5 & 293 & 71.5 & 190 & 72 \\
\hline Nil & 51 & 40.5 & 117 & 28.5 & 74 & $28 P=0.02,2 \mathrm{df}$ \\
\hline Total antibiotic/antiseptic & 89 & 70.6 & 302 & 73.7 & 204 & 77.3 \\
\hline No antibiotic or antiseptic & 37 & 29.4 & 108 & 26.3 & 60 & 22.7 \\
\hline \multicolumn{7}{|l|}{ Intraoperative } \\
\hline \multicolumn{7}{|l|}{ SC antibiotic } \\
\hline Gentamycin & 18 & 14.3 & 25 & 6.1 & 5 & 1.9 \\
\hline Cefuroxime & 78 & 61.9 & 255 & 62.1 & 198 & 75 \\
\hline Cefuroxime + gentamycin & 5 & 4 & 11 & 2.7 & 0 & 0 \\
\hline Other & 0 & 0 & 20 & 4.9 & 19 & 7.2 \\
\hline Total antibiotics & 101 & 80.1 & 311 & 75.8 & 222 & 84.1 \\
\hline Nil & 25 & 19.8 & 99 & 24.2 & 42 & 15.9 \\
\hline \multicolumn{7}{|l|}{ IC antibiotic } \\
\hline Cefuroxime bolus & 19 & 15.1 & 39 & 9.5 & 22 & 8.3 \\
\hline Vancomycin bolus & 0 & 0 & 29 & 7.1 & 0 & 0 \\
\hline Vancomycin infusion & 0 & 0 & 33 & 8 & 0 & 0 \\
\hline Nil & 107 & 84.9 & 309 & 75.4 & 242 & 91.7 \\
\hline \multicolumn{7}{|l|}{ Antibiotic/antiseptic eyedrops } \\
\hline Eyedrops + SC/IC antibiotic & 6 & 4.8 & 66 & 16.1 & 42 & 15.9 \\
\hline Eyedrops alone & 4 & 3.2 & 16 & 3.9 & 0 & 0 \\
\hline Total eyedrops & 10 & 7.9 & 82 & 20 & 42 & 15.9 \\
\hline Nil & 116 & 92.1 & 328 & 80 & 222 & 84.1 \\
\hline Gentamycin & 4 & 3.2 & 10 & 2.4 & 25 & 9.5 \\
\hline Chloramphenicol & 12 & 9.5 & 33 & 8 & 55 & 20.8 \\
\hline Povidone-iodine & 7 & 5.5 & 13 & 3.2 & 0 & 0 \\
\hline Fusidic acid & 0 & 0 & 6 & 1.5 & 0 & 0 \\
\hline \multicolumn{7}{|l|}{ Postoperative antibiotic drops } \\
\hline Polymyxin B and neomycin (maxitrol) & 61 & 48.4 & 175 & 42.7 & 79 & 29.9 \\
\hline Neomycin (betnesol-N) & 15 & 11.9 & 113 & 27.6 & 72 & 27.3 \\
\hline Total neomycin & 76 & 60.3 & 288 & 70.2 & 151 & 57.2 \\
\hline Chloramphenicol & 39 & 30.9 & 80 & 19.5 & 94 & 35.6 \\
\hline Tobramycin, flouroquinolone, other & 9 & 7.1 & 28 & 6.8 & 10 & 3.8 \\
\hline Nil (steroid only) & 2 & 1.6 & 14 & 3.4 & 9 & 3.4 \\
\hline
\end{tabular}

incidence rate of postoperative endophthalmitis, this effect was small and was not statistically significant. ${ }^{16}$ The predominant UK practice of not using a preoperative antibiotic is supported by the fact that one drop of $5 \%$ povidone-iodine preoperatively is equivalent to topical antibiotic used three times a day for 3 days in reducing ocular surface flora. ${ }^{17}$

\section{Intraoperative prophylaxis}

\section{Subconjunctival antibiotics}

This was the most commonly used means of intraoperative prophylaxis in this survey, but still has no well-designed prospective trials in its favour, and large literature reviews have not recommended it as effective 
prophylaxis. ${ }^{18}$ Two retrospective studies in the UK have shown an association between non-administration of subconjunctival cefuroxime and $\mathrm{POE}^{19,20}$ and a German survey ${ }^{14}$ suggested that subconjunctival antibiotics decrease the incidence of endophthalmitis. The absence of any cases of POE in a series of 8856 consecutive cataract extractions has been used to support the administration of subconjunctival antibiotics. ${ }^{21}$ Although the toxicity of subconjunctival gentamycin to the conjunctiva has been demonstrated, ${ }^{22} 6 \%$ of consultants in this study still use it as their primary means of intraoperative prophylaxis; most consultants used this only if there was allergy to cephalosporins.

\section{Intracameral antibiotics}

The best and most recent evidence for intracameral antibiotics is the ESCRS multicentre, prospective, randomised partially-blind study which showed a fivefold reduction in endophthalmitis rates with intracameral cefuroxime use. ${ }^{16}$ In a national 3-year prospective uncontrolled survey conducted in Sweden, a statistically significant reduction in POE was found in patients who had received intracameral cefuroxime in comparison to those treated with topical or subconjunctival antibiotics. ${ }^{23}$ The most recent UK survey on prophylactic measures did not report on intracameral bolus antibiotic use. ${ }^{10}$ The North of England survey in 2003 reported its use in $10 \%$ of those surveyed ${ }^{11}$ and it is apparent that the intracameral antibiotic use in the UK has increased (13.6\% in our survey). The safety and kinetics of intracameral cefuroxime have been well evaluated. $^{24,25}$ There has been only one report of an anaphylactic reaction to intracameral cefuroxime in a penicillin-allergic patient. $^{26}$

The rationale for intracameral administration of antibiotic is to achieve a guaranteed bactericidal concentration in the anterior chamber. Intracameral cefuroxime achieves higher aqueous concentration $(756 \mathrm{mg} / \mathrm{l})^{24} 1 \mathrm{~h}$ after surgery than subconjunctival cefuroxime ( $20 \mathrm{mg} / \mathrm{l}){ }^{27}$ Endocapsular antibiotic may even be more effective. Gimbel et $a l^{28}$ used irrigating gentamycin and vancomycin in the capsular bag at the end of surgery and reported no endophthalmitis in 11,748 procedures.

\section{Infusion antibiotics}

The predominant intraocular use of antibiotics in the US $^{29}$ and Germany ${ }^{14}$ is as an infusate in the irrigating fluid, most commonly vancomycin alone or in combination with gentamycin. It is uncommon elsewhere $\mathrm{e}^{10,30}$ as found in our study. Although safe, routine prophylactic vancomycin use is discouraged because of a lack of scientific evidence for an effect on POE rates and fear of developing resistance. ${ }^{7,31}$

\section{Postoperative antibiotics}

Few consultants in our survey used no antibiotic at all postoperatively. The rationale for their use is to reduce ocular surface bacterial contamination and achieve bacteriostatic and bactericidal anterior chamber levels, potentially eliminating postoperative microcontamination and preventing POE. Studies on postoperative antibiotic use are sparse, despite common use. One retrospective study showed that commencing topical antibiotics on the day of surgery, rather than the following day, significantly reduced POE rates. ${ }^{32}$ The duration of antibiotic use was $>2$ weeks for $70 \%$ of the surgeons we surveyed. It has been suggested that postoperative antibiotic drops be limited to one week to prevent the emergence of antibiotic resistance, ${ }^{32}$ and the ESCRS guidelines recommend no more than 2 weeks unless medically indicated.

\section{Neomycin vs chloramphenicol}

Nearly $2 / 3$ of the surgeons surveyed employed the use of a neomycin-containing eyedrop (betnesol-N or maxitrol). Maxitrol contains polymixin B as well, which provides some Gram-negative cover. The remaining 1/3 used an antibiotic eyedrop (usually chloramphenicol) and a separate steroid eyedrop. Neomycin is well known for its allergic response in $4 \%$ of patients and more importantly its lack of activity against the Gram-positive bacteria, mainly coagulase-negative staphylococcus (CNS), ${ }^{33}$ which are the most common ocular surface organisms and the major cause of POE. Chloramphenicol provides better activity against CNS than neomycin and chloramphenicol is comparable to fourth generation flouroquinolones against CNS. ${ }^{33}$

\section{Chloramphenicol vs flouroquinolones}

Aminoglycosides (except neomycin) and the fluoroquinolones, particularly levofloxacin provide better coverage against Gram-positive and Gramnegative bacteria than chloramphenicol. ${ }^{34}$ In our study, very few consultants used flouroquinolones postoperatively. This is markedly different from the USA where flouroquinolones are used routinely postoperatively. ${ }^{3}$ One study correlated reduction of endophthalmitis rates with ofloxacin vs ciprofloxacin use and recommended the newer flouroquinolones, gatifloxacin or moxifloxacin, in light of resistance to second generation flouroquinolones. ${ }^{32}$ There is, however, a large rate of cross resistance for Staphylococci between all the fluoroquinolone generations. ${ }^{35}$ Compared to the first and second generation flouroquinolones, chloramphenicol is less expensive and exhibits similar resistance among CNS, less resistance in Streptococcus species but more frequent resistance by Gram-negative bacteria. $^{34}$ 


\section{Conclusions}

We present an up-to-date, high response rate survey of antibiotic and antiseptic POE prophylaxis use by UK cataract surgeons. We have analysed the findings in the context of current knowledge on the efficacy of various forms of POE prophylaxis. A significant minority $(1 / 3 \mathrm{rd})$ are failing to use preoperative conjunctival povidone iodine, despite its widespread acceptance as the only convincingly proven prophylactic method. Subconjunctival cefuroxime is still the predominant antibiotic prophylaxis although intracameral bolus antibiotics are starting to gain acceptance and their use is strongly supported by the recent ESCRS multicentre prospective study. The widespread use of postoperative neomycin is illogical given its inadequate spectrum of activity against the likely causative agents of POE and a high rate of allergy.

The authors received no funding for this study. The authors have no proprietary interest in any of the products named.

\section{References}

1 Liesegang TJ. Use of antimicrobials to prevent postoperative infection in patients with cataracts. Curr Opin Ophthalmol 2001; 12(1): 68-74.

2 West ES, Behrens A, McDonnell PJ, Tielsch JM, Schein OD. The incidence of endophthalmitis after cataract surgery among the U.S. Medicare population increased between 1994 and 2001. Ophthalmology 2005; 112(8): 1388-1394.

3 Olson RJ. Reducing the risk of postoperative endophthalmitis. Surv Ophthalmol 2004; 49(Suppl 2): S55-S61.

4 Endophthalmitis Vitrectomy Study Group. Results of the Endophthalmitis Vitrectomy Study. A randomized trial of immediate vitrectomy and of intravenous antibiotics for the treatment of postoperative bacterial endophthalmitis. Arch Ophthalmol 1995; 113(12): 1479-1496.

5 www.rcophth.ac.uk/docs/profstands/ophthalmicservices/endophthalmitis.pdf.

6 American Academy of Ophthalmology Anterior Segment Panel. Preferred Practice Pattern Cataract in the adult eye 2001.

7 Barry P, Behrens-Baumann W, Pleyer U, Seal D. ESCRS guidelines on prevention, investigation and management of postoperative endophthalmitis, version 1. July 2005.

8 Royal College of Ophthalmologists. The Directory of Training Posts 2005-6. Hawker Publications: London, 2005.

9 Directory of Ophthalmology Care 2006. CMA Medical Data. Loughborough, 2006.

10 Dinakaran S, Crome DA. Prophylactic measures prevalent in the United Kingdom. J Cataract Refract Surg 2002; 28: 387-388.

11 Gupta M, McKee H, Stewart O. Perioperative prophylaxis for cataract surgery: survey of ophthalmologists in the north of England. J Cataract Refract Surg 2004; 30: 2021-2022.

12 Liesgang TJ. Prophylactic antibiotics in cataract operations. Mayo Clinic Proc 1997; 72: 149-159.
13 Speaker MG, Menikoff JA. Prophylaxis of endophthalmitis with topical povidone-iodine. Ophthalmology 1991; 98: 1769-1775.

14 Schmitz S, Dick HB, Krummenauer F, Pfeiffer N. Endophthalmitis in cataract surgery: results of a German survey. Ophthalmol 1999; 106: 1869-1877. conjunctiva. Arch Ophthalmol 1984; 102: 728-729.

15 Ferguson AW, Scott JA, McGavigan J, Elton RA, McLean J, Schmidt $\mathrm{U}$ et al. Comparison of $5 \%$ povidone-iodine solution against $1 \%$ povidone-iodine solution in preoperative cataract surgery antisepsis: a prospective randomised double blind study. Br J Ophthalmol 2003; 87(2): 163-167.

16 Barry P, Seal DV, Gettinby G, Lees F, Peterson M, Revie CW, ESCRS Endophthalmitis Study Group. ESCRS study of prophylaxis of postoperative endophthalmitis after cataract surgery: Preliminary report of principal results from a European multicenter study. J Cataract Refract Surg 2006; 32(3): 407-410. Erratum in: J Cataract Refract Surg 2006; 32(5): 709 .

17 Apt L, Isenberg SJ, Yoshimori R, Spierer A. Outpatient topical use of povidone-iodine in preparing the eye for surgery. Ophthalmology 1989; 96(3): 289-292.

18 Ciulla TA, Starr MB, Masket S. Bacterial endophthalmitis prophylaxis for cataract surgery: an evidence-based update. Ophthalmology 2002; 109: 13-26.

19 Lehmann OJ, Roberts CJ, Ikram K, Campbell MJ, McGill JI. Association between nonadministration of subconjunctival cefuroxime and postoperative endophthalmitis. J Cataract Refract Surg 1997; 23(6): 889-893.

20 Mandal K, Hildreth A, Farrow M, Allen D. Investigation into postoperative endophthalmitis and lessons learned. J Cataract Refract Surg 2004; 30(9): 1960-1965.

21 Colleaux KM, Hamilton WK. Effect of prophylactic antibiotics and incision type on the incidence of endophthalmitis after cataract surgery. Can J Ophthalmol 2000; 35(7): 373-378

22 Jenkins CD, McDonnell PJ, Spalton DJ. Randomised single blind trial to compare the toxicity of subconjunctival gentamicin and cefuroxime in cataract surgery. $\mathrm{Br} \mathrm{J}$ Ophthalmol 1990; 74(12): 734-738.

23 Wejde G, Montan P, Lundstrom M, Stenevi U, Thorburn W. Endopthalmitis following cataract surgery in Sweden: national prospective survey 1999-2001. Acta Ophthalmol Scand 2005; 83: 7-10.

24 Montan PG, Wejde G, Setterquist H, Rylander M, Zetterstrom C. Prophylactic intracameral cefuroxime. Evaluation of safety and kinetics in cataract surgery. J Cataract Refract Surg 2002; 28(6): 982-987.

25 Gupta MS, McKee HD, Saldana M, Stewart OG. Macular thickness after cataract surgery with intracameral cefuroxime. J Cataract Refract Surg 2005; 31(6): 1163-1166.

26 Villada JR, Vicente U, Javaloy J, Alio JL. Severe anaphylactic reaction after intracameral antibiotic administration during cataract surgery. J Cataract Refract Surg 2005; 31(3): 620-621.

27 Jenkins, Tuft BJO, Jenkins CD, Tuft SJ, Sheraidah G, McHugh DA, Buckley RJ. Comparative intraocular penetration of topical and injected cefuroxime. $\mathrm{Br} J$ Ophthalmol 1996; 80(8): 685-688.

28 Gimbel HV, Sun R, Debrof BM. Prophylactic intracameral antibiotics during cataract surgery. The incidence of endophthalmitis and corneal endothelial cell loss. Eur J Implant Refract Surg 1994; 6: 280-285. 
29 Leaming DV. Practice styles and preferences of ASCRS members-2003 survey. J Cataract Refract Surg 2004; 30: 892-900.

30 Morlet N. Gatus B, Coroneo M: Patterns of perioperative prophylaxis for cataract surgery: a survey of Australian ophthalmologists. Aust NZJ Ophthalmol 1998; 26: 5-12.

31 American Academy of Ophthalmology. New information statement, American Academy of Ophthalmology and Centres for Disease Control and Prevention joint information statement on the prophylactic use of vancomycin for intraocular surgery. The Eye M.D. Association: San Francisco, 1999.

32 Wallin T, Parker J, Jin Y, Kefalopoulos G, Olson RJ. Cohort study of 27 cases of endophthalmitis at a single institution. J Cataract Refract Surg 2005; 31(4): 735-741.
33 Arantes TE, Cavalcanti RF, Diniz MD, Severo MS, Lins Neto J, Castro CM. Conjunctival bacterial flora and antibiotic resistance pattern in patients undergoing cataract surgery. Arq Bras Oftalmol 2006; 69(1): 33-36 (E-pub 2006 February 10)

34 Ta CN, Chang RT, Singh K, Egbert PR, Shriver EM, Blumenkranz MS, Mino de Kaspar H. Antibiotic resistance patterns of ocular bacterial flora: a prospective study of patients undergoing anterior segment surgery. Ophthalmology 2003; 110(10): 1946-1951.

35 Miller D, Flynn PM, Scott IU, Alfonso EC, Flynn Jr HW. In vitro fluoroquinolone resistance in staphylococcal endophthalmitis isolates. Arch Ophthalmol 2006; 124(4): 479-483. 